\title{
Assessment of baroreceptor-cardiac reflex sensitivity using time domain analysis in patients with IDDM and the relation to left ventricular mass index
}

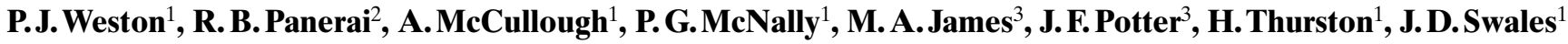 \\ ${ }^{1}$ Department of Medicine and Therapeutics, Clinical Sciences Building, Leicester Royal Infirmary, Leicester, UK \\ ${ }^{2}$ Department of Medical Physics, Leicester Royal Infirmary, Leicester, UK \\ ${ }^{3}$ Division of Medicine for the Elderly, Glenfield General Hospital, Leicester, UK
}

Summary Autonomic dysfunction in insulin-dependent diabetic (IDDM) patients has been associated with abnormalities of left ventricular function and an increased risk of sudden death. A group of 30 patients with IDDM and 30 age, sex and blood pressure matched control subjects underwent traditional tests of autonomic function. In addition, baroreceptor-cardiac reflex sensitivity (BRS) was assessed using time domain (sequence) analysis of systolic blood pressure and pulse interval data recorded non-invasively using the Finapres beat-to-beat blood pressure recording system. 'Up BRS' sequences-increases in systolic blood pressure associated with lengthening of R-R interval, and 'down BRS' sequences-decreases in systolic blood pressure associated with shortening of $\mathrm{R}$ $\mathrm{R}$ interval were identified and BRS calculated from the regression of systolic blood pressure on R-R interval for all sequences. We also assessed heart rate variability using power spectral analysis and, after expressing components of the spectrum in normalised units, assessed sympathovagal balance from the ratio of low to high frequency powers. IDDM subjects underwent 2-D echocardiography to assess left ventricular mass index. Standard tests of autonomic function revealed no differences between IDDM patients and control subjects, but dramatic reductions in baroreceptor-cardiac reflex sensitivity were detected in IDDM patients. 'Up BRS' when supine was 11.2 \pm $1.5 \mathrm{~ms} / \mathrm{mmHg}$ (mean \pm SEM) compared with $20.4 \pm$ 1.95 in control subjects $(p<0.003)$ and when standing was $4.1 \pm 1.9$ vs $7.6 \pm 2.7 \mathrm{~ms} / \mathrm{mmHg}(p<0.001)$. Down
BRS when supine was $11.5 \pm 1.2$ vs $22 \pm 2.6$ $(p<0.001)$ and standing was $4.4 \pm 1.9 \mathrm{vs} 7.3 \pm 2.5 \mathrm{~ms} /$ $\mathrm{mmHg}(p<0.003)$. There were significant relations between impairment of the baroreflex and duration of diabetes $(p<0.001)$ and poor glycaemic control $(p<0.001)$. From a fast Fourier transformation of supine heart rate data and using a band width of $0.05-$ $0.15 \mathrm{~Hz}$ as low-frequency and $0.2-0.35 \mathrm{~Hz}$ as high frequency total spectral power of R-R interval variability was significantly reduced in the IDDM group for both low-frequency $\left(473 \pm 62.8\right.$ vs $746.6 \pm 77.6 \mathrm{~ms}^{2}$ $p=0.002$ ) and high frequency bands $125.2 \pm 12.9 \mathrm{vs}$ $459.3 \pm 89.8 \mathrm{~ms}^{2} p<0.0001$. When the absolute powers were expressed in normalised units the ratio of low frequency to high frequency power (a measure of sympathovagal balance) was significantly increased in the IDDM group $(2.9 \pm 0.53$ vs $4.6 \pm 0.55$, $p<0.002$ supine: $3.8 \pm 0.49$ vs $6.6 \pm 0.55, p<0.001$ standing). Thus, time domain analysis of baroreceptor-cardiac reflex sensitivity detects autonomic dysfunction more frequently in IDDM patients than conventional tests. Impaired BRS is associated with an increased left ventricular mass index and this abnormality may have a role in the increased incidence of sudden death seen in young IDDM patients. [Diabetologia (1996) 39: 1385-1391]

Keywords Baroreceptor-cardiac reflex sensitivity, time domain analysis, autonomic function, left ventricular mass index.
Corresponding author: Dr. P. Weston, Department of Medicine and Therapeutics, Clinical Sciences Building, Leicester Royal Infirmary, Leicester LE2 7 LX, UK
Abbreviations: BRS, Baroreceptor-cardiac reflex; IDDM, insulin-dependent diabetes mellitus. 
For the past 25 years evidence of autonomic dysfunction has been sought by using a battery of non-invasive cardiovascular reflex tests assessing heart rate and blood pressure changes during a variety of manoeuvres [1].

With improved technology, baroreceptor-cardiac reflex sensitivity (BRS) is increasingly used to assess autonomic function in diabetic patients $[2,3]$. Traditionally, BRS is assessed by measuring the changes in R-R interval produced in reflex to acute pharmacologically induced changes in blood pressure $[4,5]$. Previously, this technique has required arterial cannulation for the measurement of beat-to-beat changes in blood pressure. However, this limitation has recently been overcome with the development of noninvasive beat-to-beat blood pressure measurement systems such as the Finapres device (Ohmeda 2300, Englewood, Col., USA) [6]. This device, using a modified version of the volume clamp method described by the Czech physiologist Peñáz [7] reliably records beat-to-beat blood pressure, non-invasively, from a digital artery. Long periods of data recording (up to $30 \mathrm{~min}$ ) have been made with the servo mechanism deactivated; the observed blood pressures are comparable to those obtained by brachial intra-arterial measurement with an offset (usually around $5 \mathrm{mmHg}$ ) that remains constant throughout the recording [8]. Pharmacological agents have the theoretical disadvantage of altering the viscoelastic properties of the aorta thus potentially influencing BRS [9] so other methods of assessing BRS have been sought. One alternative approach, which has again been validated against intra-arterial recordings [10], involves computer identification of sequences of three or more consecutive beats characterized either by a progressive increase in systolic blood pressure followed by a linearly related lengthening in pulse interval ('Up BRS' sequences) or by a progressive reduction in systolic blood pressure followed by a linearly related shortening of pulse interval ('Down BRS' sequences). The slope of the regression line between systolic blood pressure and pulse interval changes is taken as an index of BRS [10-12]. These sequences are virtually eliminated following sinoaortic denervation, implying they result from baroreflex modulation of the sinus node [13].

Abnormalities of baroreceptor-cardiac reflex sensitivity in rats have been associated with an increase in left ventricular mass independent of systolic blood pressure [14] although such data in humans is lacking. The mechanism leading to this increase is unclear but was associated with an impairment of vagal function. Using spectral analysis methods to study heart rate variability allows quantification of individual vagal and sympathetic influences on the heart [15-17]. The power spectrum of heart rate variability has been shown to consist of three major peaks-very low, low and high frequency. Heart rate fluctuations in the low frequency band $(0.08-0.12 \mathrm{~Hz})$ are said to represent predominately sympathetic function with a contribution from the parasympathetic system, while the high frequency peak $(0.15-0.4 \mathrm{~Hz})$ is said to reflect parasympathetic or vagal activity [17]. Thus, an approximate estimate of sympathovagal balance can be derived from the ratio of low to high-frequency spectral powers $[17,18]$. Accordingly, we assessed autonomic function using standard bedside cardiovascular reflex tests in a group of insulin-dependent diabetic (IDDM) patients and a group of age and sex matched control subjects. Autonomic function was explored further by spectral analysis of resting heart rate variability. BRS was assessed using sequence analysis of non-invasive continuously recorded systolic blood pressure and pulse interval data recorded while supine or standing. The aim of the study was to compare BRS recorded in this way with standard cardiovascular reflex tests and to examine whether IDDM patients exhibited impairment of autonomic function not demonstrated by the standard tests. The relation between BRS and left ventricular mass index was also assessed.

\section{Patients and methods}

Subjects. We studied 30 IDDM patients aged between 20 and 54 (mean \pm SEM $34.8 \pm 1.5$ ) years and 30 age, sex and blood pressure matched non-diabetic control subjects. Patients were recruited from the diabetic clinic at the Leicester Royal Infirmary and all gave informed consent; all had a history of ketonuria at the time of diagnosis. Patients with evidence of microvascular disease (i.e. those with microalbuminuria, retinopathy or clinical evidence of neuropathy) were excluded as were those with clinical evidence of peripheral vascular disease or a history of cerebrosvascular disease. Patients were all normotensive with clinic blood pressure of $140 / 90 \mathrm{mmHg}$ or less on at least three occasions and were not taking medication other than insulin. Control subjects were recruited from volunteers among the hospital staff. All had a random blood glucose level of less than $6 \mathrm{mmol} / \mathrm{l}$ and were excluded if they had any underlying medical conditions or if clinic blood pressure was $140 / 90 \mathrm{mmHg}$ or more.

Protocol. Subjects attended the test laboratory at least $2 \mathrm{~h}$ after eating and the tests were performed in a quiet room with the temperature controlled between $20-24^{\circ} \mathrm{C}$. All subjects had height and weight measured, from which body mass index was calculated, and waist/hip ratio was also measured. All subjects performed five standard cardiovascular tests of autonomic function [1].

After resting for $10 \mathrm{~min}$ the Finapres cuff was applied to the middle finger of the left hand and a surface ECG fitted to record R-R interval. Subjects were initially supine with the arm supported at the level of the right atrium and patients were asked not to talk. The Finapres was calibrated and when stable, resting systolic blood pressure and R-R interval recorded for 15 min. During this time the self-servo mechanism of the Finapres was disabled. The subjects were then asked to stand, again with the arm supported at the level of the right atrium, and after a 5-min resting period, during which the Finapres was again calibrated, the systolic blood pressure and R-R interval 
recorded for a further $15 \mathrm{~min}$. The respiratory rate was monitored throughout the recording periods and recording stopped if the respiratory rate fell below 15 breaths per min. Data were converted from analogue to digital using an on-line personal computer sampling at $200 \mathrm{~Hz}$. A QRS detection algorithm was employed to automatically mark the R-R intervals (from the surface ECG). The computer software also detected increases and decreases in systolic blood pressure and compared these to changes in R-R interval. Where three or more consecutive systolic blood pressure readings increased by $0.5 \mathrm{mmHg} / \mathrm{s}$ or more the pulse interval was automatically compared and if $\mathrm{R}-\mathrm{R}$ interval lengthened this was counted as an 'up BRS' sequence. Similarly, where systolic blood pressure decreased by $0.5 \mathrm{mmHg} / \mathrm{s}$ or more for three or more consecutive readings and this was associated with a decrease in R-R interval this was counted as a 'down BRS' sequence. BRS was determined from the regression of R-R interval on systolic blood pressure for all up, down and non-BRS sequences (i.e. where changes in systolic blood pressure were not associated with changes in $\mathrm{R}-\mathrm{R}$ interval). Only regression lines with a correlation coefficient of 0.8 or more and significant at $p<0.05$ were used and an average BRS for all of the up and down BRS sequences was calculated. To ensure Finapres readings were an accurate measure of systolic blood pressure syphgmomanometer recordings were taken before and after recording periods.

Finally, power spectra of pulse interval data were estimated using a fast Fourier transformation of supine and standing heart rate data. Briefly, three segments of data with 512 samples each were used to estimate the power spectra of R-R interval for each patient by means of a fast Fourier transform algorithm after removing linear trends and applying a cosine tapered window. As well as expressing the absolute values of the low frequency and high frequency powers the relative value of each power component independent of the total power and the very low frequency component was assessed by expressing the powers in normalised units [17].

Blood was taken to determine $\mathrm{HbA}_{1}$, creatinine and cholesterol levels. A survey of the diabetic patients' notes was undertaken and $\mathrm{HbA}_{1}$ values for the duration of their disease were recorded and averaged (records dating back to 1978 were available). In addition, all IDDM patients underwent transthoracic 2D-echocardiography to assess left ventricular mass index. Measurements were performed from M-mode echos derived from 2D echocardiograms using the Hewlett Packard Sonos 1500 system (Hewlett-Packard Co, Boise, Idaho, USA). The patients were in the left lateral decubitus position with the left arm raised supporting the head. Left ventricular mass was calculated using the formula described elsewhere [19] and was corrected for body surface area to give the left ventricular mass index. Three consecutive cycles were taken for measurement and the average was used as the left ventricular mass index. The echocardiographic studies were performed by a single trained technician unaware of the results of other parts of the study.

Reproducibility of BRS. Sequence BRS was measured again after a median interval of 3 weeks (range 2-12 weeks) in 12 subjects (10 control and 2 diabetic subjects). The intra-individual coefficient of variation (CV) between the two study days was $16.2 \%$ for the total BRS sequences and $16 \%$ for the 'up BRS' sequences, $17.3 \%$ for the 'down BRS' sequences. Reproducibility of the spectral power data was also assessed and the $\mathrm{CV}$ for the low frequency band was $18.2 \%$ and for the high frequency band $16.7 \%$.

Statistical analysis. Results are expressed as mean \pm SEM. Between-group comparisons were made using Student's twotailed unpaired $t$-test (after testing for normality using the
Table 1. Characteristics of subjects studied

\begin{tabular}{lll}
\hline & $\begin{array}{l}\text { Control subjects } \\
(n=30)\end{array}$ & $\begin{array}{l}\text { IDDM patients } \\
(n=30)\end{array}$ \\
\hline Age (years) & $34 \pm 1.5$ & $34.8 \pm 1.6$ \\
Duration of diabetes (years) & - & $15.6 \pm 1.5$ \\
$\mathrm{HbA}_{1}(\%)$ & $5.8 \pm 0.6^{\mathrm{b}}$ & $10 \pm 0.3^{\mathrm{a}}$ \\
$\begin{array}{l}\text { Creatinine }(\mu \mathrm{mol} / \mathrm{ml}) \\
\begin{array}{l}\text { Systolic blood pressure } \\
\text { (mmHg) }\end{array}\end{array}$ & $97 \pm 3.7$ & $97 \pm 2.7$ \\
$\begin{array}{l}\text { Diastolic blood pressure } \\
\text { (mmHg) }\end{array}$ & $125 \pm 3.9$ & $128 \pm 2.9$ \\
$\begin{array}{l}\text { Body mass index }\left(\mathrm{kg} / \mathrm{m}^{2}\right) \\
\text { Waist/hip ratio }\end{array}$ & $26.2 \pm 0.8$ & $25.2 \pm 0.7$ \\
\hline Data are mean $\pm \mathrm{SEM}$ & $0.86 \pm 0.04$ & $0.84 \pm 0.03$ \\
\hline
\end{tabular}

Data are mean \pm SEM.

${ }^{a}$ Average $\mathrm{HbA}_{1}$ since diagnosis.

${ }^{\mathrm{b}} p<0.001$

Table 2. Standard clinical tests of autonomic function

\begin{tabular}{llll}
\hline & $\begin{array}{l}\text { Control } \\
\text { subjects }\end{array}$ & $\begin{array}{l}\text { IDDM } \\
\text { patients }\end{array}$ & $p$ value \\
\hline $\begin{array}{l}\text { Valsalva ratio } \\
\begin{array}{l}\text { Expiration/inspiration } \\
\text { (beats/min) }\end{array}\end{array}$ & $1.75 \pm 0.4$ & $1.70 \pm 0.09$ & 0.74 \\
$30: 15$ ratio & $1.37 \pm 0.03$ & $1.36 \pm 0.02$ & 0.8 \\
$\begin{array}{l}\text { Blood pressure handgrip } \\
\text { (mmHg) }\end{array}$ & $32 \pm 0.3$ & $32 \pm 0.2$ & 0.72 \\
$\begin{array}{l}\text { Blood pressure L-S } \\
\text { (mmHg) }\end{array}$ & $5 \pm 1.0$ & $4 \pm 0.5$ & 0.61 \\
\hline
\end{tabular}

Data are mean \pm SEM

LS, Standing minus systolic blood pressure lying

Shapiro-Wilk $W$ test). The relations between BRS and continuous variables such as age, duration of diabetes and $\mathrm{HbA}_{1}$ were assessed using Pearson's correlation coefficient and least squares regression analysis. A $p$ value of less than 0.05 was regarded as statistically significant.

\section{Results}

The 30 control subjects were closely matched for age and systolic blood pressure with the 30 IDDM patients (Table 1 ), only $\mathrm{HbA}_{1}$ was significantly higher in the IDDM group. There were no differences in the standard tests of autonomic function between IDDM patients and control subjects (Table 2). BRS was significantly reduced in the IDDM group compared to the control population for both 'up' and 'down' sequences regardless of position (Table 3, Fig. 1). Furthermore, the IDDM subjects had significantly fewer up and down sequences than the control population independent of position (Table 3). There was a significant age-related decline in the control group BRS (Fig. $1 r=-0.58 p<0.001$ while supine and $r=-0.67 p<0.001$ while standing) which was not seen in the IDDM patients. Furthermore, in the 
Table 3. Comparison of baroreflex sensitivity (BRS) in IDDM patients compared to control subjects

\begin{tabular}{|c|c|c|c|c|c|c|}
\hline & $\begin{array}{l}\text { Diabetic up } \\
\text { sequences }\end{array}$ & $\begin{array}{l}\text { Control up } \\
\text { sequences }\end{array}$ & $p$ value & $\begin{array}{l}\text { Diabetic down } \\
\text { sequences }\end{array}$ & $\begin{array}{l}\text { Control down } \\
\text { sequences }\end{array}$ & $p$ value \\
\hline Supine BRS (ms/mmHg) & $11.2 \pm 1.5$ & $20.4 \pm 1.95$ & $<0.003$ & $11.5 \pm 1.2$ & $22 \pm 2.6$ & $<0.001$ \\
\hline Standing BRS $(\mathrm{ms} / \mathrm{mmHg})$ & $4.1 \pm 1.9$ & $7.6 \pm 2.7$ & $<0.001$ & $4.4 \pm 1.9$ & $7.3 \pm 2.5$ & $<0.003$ \\
\hline Total number standing & $16.2 \pm 3.1$ & $41.5 \pm 5.7$ & $<0.001$ & $28.4 \pm 3.2$ & $48.2 \pm 7.1$ & $<0.001$ \\
\hline
\end{tabular}

Data are mean \pm SEM

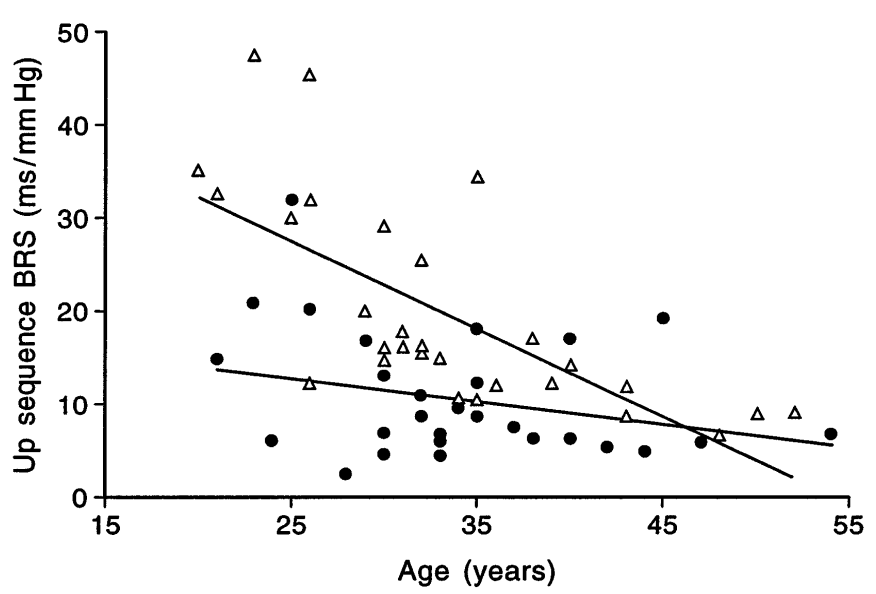

Fig. 1. 'Up sequence' baroreceptor-cardiac reflex sensitivity compared to age for the control $(\triangle)$ and IDDM $(\bullet)$ populations while supine. (For control population $r=-0.58$ $p<0.001$; for IDDM $r=-0.27 p=0.15$ )

IDDM group BRS was lower in patients with a longer duration of diabetes when measured supine (Fig. 2 $r=-0.6 p<0.001$ for up sequences and $r=-0.48$ $p<0.01$ for down sequences) and standing $(r=-0.5$ $p<0.001$ for up sequences and $r=-0.52 p<0.001$ for down sequences). There was a significant inverse relation between $\mathrm{BRS}$ and average $\mathrm{HbA}_{1}$ in the diabetic subjects and this was again seen supine (Fig. 3 $r=-0.59 p<0.001$ for up and down sequences) and standing $(r=-0.5 p<0.001$ for up sequences and $r=-0.58 p<0.001$ for down sequences). Spectral analysis of heart rate variability both supine and standing revealed significant reductions in absolute values of low and high frequency powers in the diabetic group compared to the control group and this difference persisted when values were expressed in normalised units, which are independent of total power and the very low frequency component (Table 4 and Table 5 and Fig. 4 a, b). The ratio of low frequency to high frequency power, when expressed as normalised units (a measure of sympathovagal balance) was significantly increased in the IDDM group both supine $(2.9 \pm 0.53$ vs $4.6 \pm 0.55, p<0.002)$ and standing $(1.9 \pm 0.53$ vs $6.6 \pm 0.75, p<0.001)$.

Two of the IDDM subjects had left ventricular mass indices that were not measurable due to technical difficulties; the average index for the IDDM subjects was $97 \pm 4.3 \mathrm{~g} / \mathrm{m}^{2}$. Three of the subjects had left

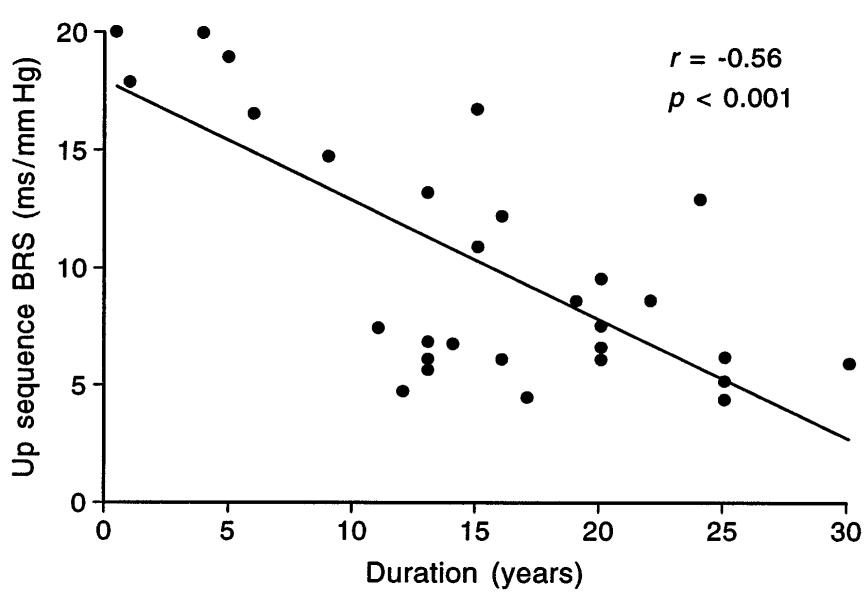

Fig. 2. Relation between 'up baroreceptor-cardiac reflex sensitivity' while supine and duration of diabetes. Similar relations were seen for down sequences and in the standing position

ventricular hypertrophy $\left(>120 \mathrm{~g} / \mathrm{m}^{2}\right)$ but were not hypertensive on repeated clinic blood pressure readings. A significant inverse relationship was seen between left ventricular mass index and BRS recorded supine (Fig. $5 r=-0.57 p<0.002$ for up sequences and $r=-0.51 p<0.002$ for down sequences) and standing $(r=-0.55 p<0.005$ for up sequences and $r=-0.58 p<0.002$ for down sequences). No correlation was seen between the standard tests of autonomic function and left ventricular mass index.

\section{Discussion}

In this study we have assessed autonomic function using standard bedside cardiovascular reflex tests [1] and with spectral analysis of supine and standing heart rate data. We have assessed baroreceptor-cardiac reflex sensitivity using time domain (sequence) analysis and attempted to explore the relation between BRS and left ventricular mass index. While none of the IDDM patients had symptoms of autonomic dysfunction and had normal bedside autonomic function tests, they showed dramatic reductions in BRS and a significant reduction in the spectral powers of heart rate variability suggestive of an abnormality of parasympathetic (vagal) activity. From the spectral data we found a relative 


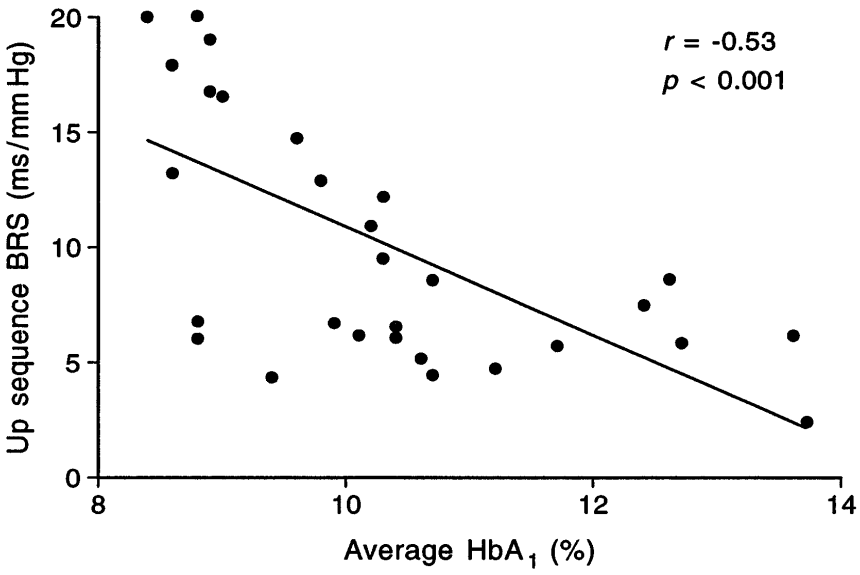

Fig.3. Relation between 'up sequence' baroreceptor-cardiac reflex sensitivity while supine and average $\mathrm{HbA}_{1}$ since diabetes diagnosis
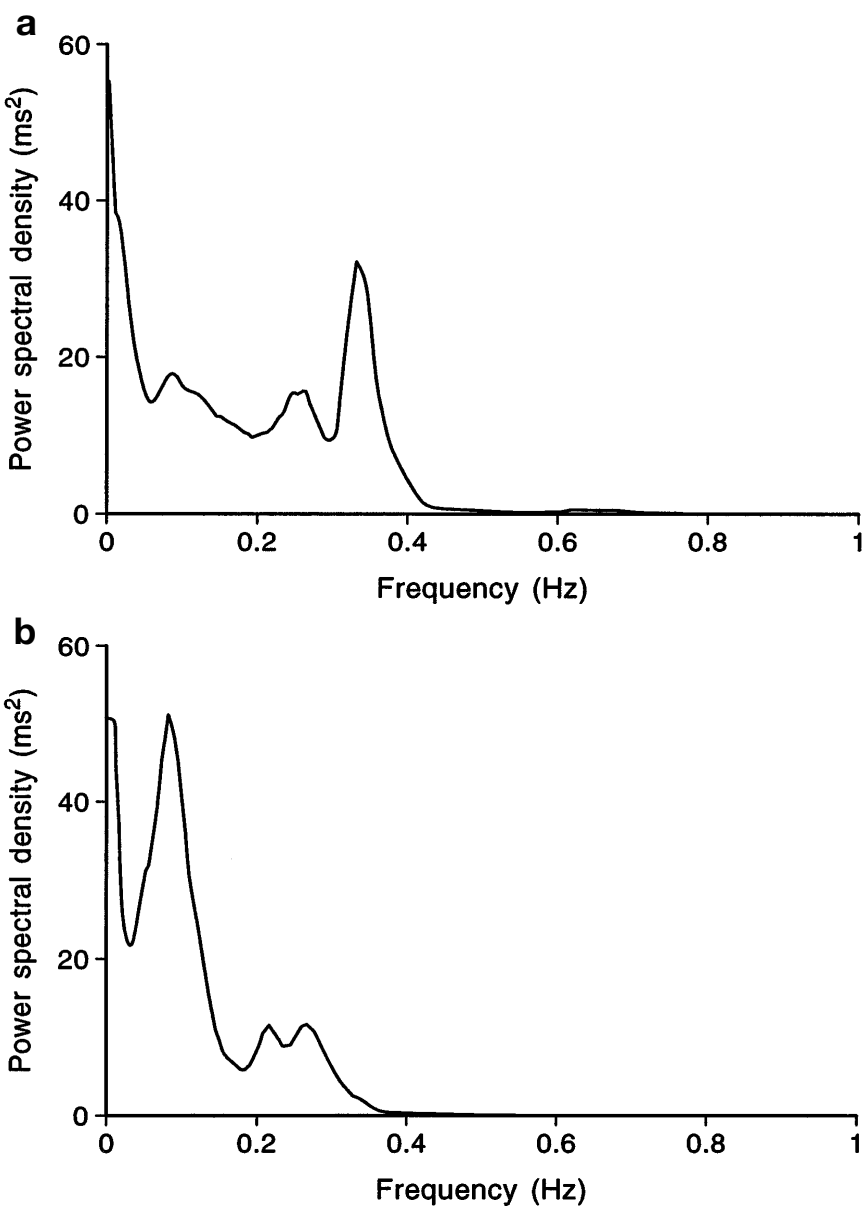

Fig. 4a, b. Power spectral density graph for control subjects showing a mid-frequency band $(0.05-0.15 \mathrm{~Hz})$ and a high frequency band $(0.2-0.35 \mathrm{~Hz})$; b Power spectral density graph for IDDM subjects, matched for age and systolic blood pressure to the patients in Figure $4 \mathrm{a}$, showing a significant reduction in the high-frequency band
Table 4. Comparison of spectral analysis results of resting, supine heart rate

\begin{tabular}{lccl}
\hline & Control subjects & IDDM patients & $p$ value \\
\hline $\begin{array}{l}\text { Power low } \\
\text { frequency }\left(\mathrm{ms}^{2}\right)\end{array}$ & $746.6 \pm 77.6$ & $473.3 \pm 62.8$ & 0.002 \\
$\begin{array}{l}\text { Power high } \\
\text { frequency }\left(\mathrm{ms}^{2}\right)\end{array}$ & $459.3 \pm 89.8$ & $125.2 \pm 12.9$ & $<0.0001$ \\
LF/HF & $2.92 \pm 0.52$ & $4.63 \pm 0.54$ & 0.0002 \\
Power LF & $62 \pm 2.3$ & $79 \pm 1.7$ & 0.002 \\
Power HF & $33 \pm 3.1$ & $22 \pm 3.1$ & 0.002 \\
LF/HF & $2.9 \pm 0.53$ & $4.6 \pm 0.55$ & 0.002 \\
\hline
\end{tabular}

Low frequency (LF: 0.05-0.15 Hz); High frequency (HF: 0.2$0.35 \mathrm{~Hz})$

${ }^{\text {a }}$ Ratio of low-frequency to high frequency power; i. e. a reflection of sympathovagal balance; ${ }^{b}$ ratio of low-frequency to high frequency normalised units; NU, Normalised units

Table 5. Comparison of spectral analysis results of resting, standing heart rate for the control and IDDM population

\begin{tabular}{lccl}
\hline & Control subjects & IDDM patients & $p$ value \\
\hline $\begin{array}{l}\text { Power low } \\
\text { frequency }\left(\mathrm{ms}^{2}\right)\end{array}$ & $600 \pm 52.3$ & $582.9 \pm 36.1$ & 0.002 \\
$\begin{array}{l}\text { Power high } \\
\text { frequency }\left(\mathrm{ms}^{2}\right)\end{array}$ & $159.3 \pm 48.5$ & $77.9 \pm 20.2$ & $<0.001$ \\
LF/HF & $3.97 \pm 0.72$ & $8.8 \pm 2.74$ & $<0.001$ \\
Power LF (nu) & $78 \pm 2.3$ & $85.8 \pm 1.7$ & 0.002 \\
Power HF (nu) & $19.9 \pm 3.1$ & $15 \pm 1.1$ & 0.004 \\
LF/HF & $3.8 \pm 0.49$ & $6.6 \pm 0.55$ & $<0.001$ \\
\hline
\end{tabular}

Data are mean \pm SEM

Low-frequency (LF: 0.05-0.15 Hz); High-frequency band (HF: $0.2-0.35 \mathrm{~Hz})$.

${ }^{\text {a }}$ Ratio of low-frequency to high frequency power; i.e. a reflection of sympathovagal balance; ${ }^{b}$ Ratio of low-frequency to high frequency normalised units

NU, Normalised units

sympathetic predominance among the IDDM population. Furthermore, there was a significant negative correlation between BRS and left ventricular mass index that was not seen with the traditional tests of cardiac autonomic function.

The Finapres has been used in baroreflex studies and has been extensively validated against intra-arterial measurements [8]. While studies of BRS in diabetic subjects have used the Finapres [3] no comparisons with intraarterial measurements have been made. Theoretically, as IDDM can affect vascular reactivity we could simply be detecting an abnormality of the digital arteries rather than a systemic abnormality of cardiovascular control. We feel this is unlikely as there was good correlation between sphygmomanometer readings and Finapres data.

Studies of the standard tests of autonomic function yield a declining score with increasing age in non-diabetic patients [20]. By contrast, in this population of 


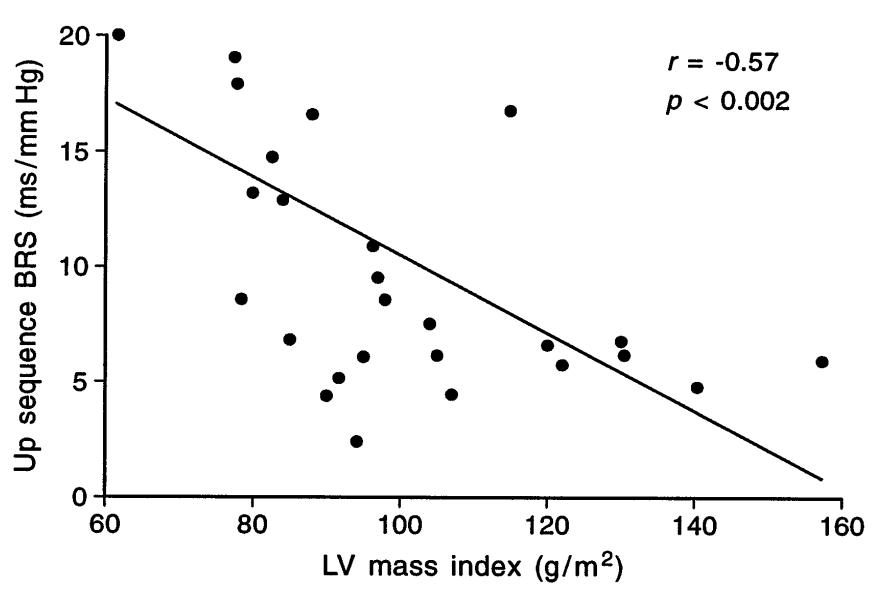

Fig. 5. Relation between 'up sequence' baroreceptor-cardiac reflex sensitivity while supine and left ventricular mass index. Similar relations were seen for up and down sequences independent of position

IDDM patients BRS was reduced and did not decline further with increasing age.

Using standard clinical tests of autonomic function to diagnose autonomic neuropathy previous investigators have found no association with duration of diabetes [21]. This observation was confirmed in our study. However, BRS showed a significant inverse relationship with duration of diabetes. Moreover, the baroreceptor-cardiac reflex function in with IDDM patients of less than 5 years duration was reduced compared to age-matched non-diabetic control subjects. Using spectral analysis, abnormalities in autonomic function can be detected in patients with IDDM of less than 6 weeks duration, despite correction of the metabolic abnormalities [22].

Recently published results have shown that hyperglycaemia is an important factor in the development and progression of diabetic microvascular complications, including neuropathy [23]. Similarly, we found hyperglycaemia as assessed by average $\mathrm{HbA}_{1}$ since diagnosis to be significantly associated with lower BRS.

BRS has been reported to be lower in the standing position compared to supine [24] and this was confirmed in our study. Both IDDM patients and control subjects had lower BRS on standing.

In the present study there were fewer 'BRS sequences' in the IDDM population compared to the control subjects. In essential hypertension, where BRS is also impaired [4], there are also fewer BRS sequences [11]. Thus, IDDM impairs the cardiac modulation that baroreceptors exert and this impairment is manifest not only as a reduced sensitivity but as a decreased rate of engagement of the baroreceptor reflex in response to progressive change in blood pressure. The spectral analysis of heart rate data has identified an abnormality of parasympathetic (vagal) function and thus a relative sympathetic predominance as implied by the higher $\mathrm{LF} / \mathrm{HF}$ ratio in the IDDM group compared to the control subjects. This imbalance between the sympathetic and parasympathetic function in part, explained the abnormality in the baroreceptor-cardiac reflex. For data recorded while supine both HF and LF powers may reflect predominately parasympathetic modulation of the heart [25] but the spectral data recorded while standing, where there is a significant sympathetic contribution to heart rate powers [25], were also abnormal in the IDDM population.

Patients with symptomatic diabetic autonomic neuropathy have been found to have abnormal ventricular systolic function on radionuclide ventriculography in the absence of ischaemic heart disease [26]. Furthermore, in IDDM patients with poor metabolic control echocardiographic evidence of abnormal left ventricular function has been observed and associated with adrenergic hypersensitivity [27]. In animal models, deficits in the baroreceptor-cardiac reflex were highly correlated with the level of cardiac hypertrophy [15]. In the IDDM patients we studied there was a significant increase in left ventricular mass index as BRS declined. Furthermore from the spectral analysis of heart rate variability we found a 'sympathetic predominance' among the diabetic group. The increase in left ventricular mass index could therefore be due to relative sympathetic overactivity, but it is also possible that changes in left ventricular mass are in some way responsible for the changes in autonomic parameters. In other clinical settings increased left ventricular mass has been associated with risk of sudden death $[28,29]$ and it is thus interesting to speculate that the increased incidence of sudden death in IDDM patients [30-32] could be due to abnormal BRS resulting in increased left ventricular mass index (possibly due to increased sympathetic predominance) and an increased risk of sudden cardiac death. Sympathetic predominance has already been associated with increased mortality in patients following myocardial infarction [33] although no assessment of left ventricular mass index has been made.

We have shown that baroreceptor-cardiac reflex sensitivity is often abnormal in asymptomatic IDDM patients. Moreover, changes in BRS were observed despite normal standard clinical tests of autonomic function. Impaired parasympathetic function, and a disruption of the usual balance between sympathetic and parasympathetic arms of the autonomic nervous system as suggested by power spectral analysis of heart rate data could explain, in part, this reduction in BRS found in the IDDM group. There was a significant negative correlation between BRS and left ventricular mass index and this may be related to a relative predominance of the sympathetic nervous system. The use of the time domain (sequence) analysis of systolic BP and pulse interval data provides a 
non-invasive technique to assess BRS. Potentially, this technique may identify those diabetic patients at risk of sudden cardiac death.

\section{References}

1. Ewing DJ, Martyn CN, Young RJ, Clarke BF (1985) The value of cardiovascular autonomic function tests: a ten year experience in diabetes. Diabetes Care 8: 491-498

2. Bennett T, Hosking DJ, Hampton JR (1976) Baroreflex sensitivity and responses to the Valsalva manoeuvre in subjects with diabetes mellitus. J Neurol Neurosurg Psychiatry 39: $178-183$

3. Ferrer MT, Kennedy WR, Sahinen F (1991) Baroreflexes in patients with diabetes mellitus. Neurology 41: 1462-1466

4. Bristow A, Honour AJ, Pickering GW, Sleight P, Smith HS (1969) Diminished baroreflex sensitivity in high blood pressure. Circulation 39: 48-54

5. Gribbin S, Pickering TG, Sleight P, Peto R (1971) Effect of age and high blood pressure on baroreflex sensitivity in man. Circ Res 29: 424

6. Molhoek GP, Wessling KH, Settels JJ (1984) Evaluation of the Penaz servo-plethsmo-manometer for the continuous non-invasive measurement of finger blood pressure. Basic Res Cardiol 79: 598-609

7. Peñáz J (1973) Photoelectric measurement of blood pressure volume and flow in the finger. In: Albert A, Vogt W, Helbig W (eds) Digest of International Conference of Medicine and Biological Engineering. Dresden, FRG

8. Parati G, Casadei R, Groppelli A, Di Rienzo M, Mancia G (1989) Comparison of finger and intra-arterial blood pressure monitoring at rest and during laboratory testing. Hypertension 13: 647-655

9. Kirchheim HR (1976) Systemic arterial baroreceptor reflexes. Pharmacol Review 56: 100-176

10. Omboni S, Parati G, Frattola A, Mutti E, Di Rienzo, Castiglioni P, Mancia G (1993) Spectral and sequence analysis of finger blood pressure variability: comparison with analysis of intra-arterial recordings. Hypertension 22: 26-33

11. Parati G, Di Rienzo M, Bertinieri G (1988) Evaluation of the baroreceptor-heart rate reflex by 24 -hour intraarterial blood pressure monitoring in humans. Hypertension 12: 214-222

12. Steptoe A, Vögele C (1990) Cardiac baroreflex function during postural change assessed using non-invasive spontaneous sequence analysis in young men. Cardiovascular Research 24: 627-632

13. Bertinieri G, Di Rienzo M, Cavallazi A, Ferrari AU, Pedotti A, Mancia G (1988) Evaluation of baroreceptor reflex by blood pressure monitoring in unanaesthetised cats. Am J Physiol 254: H377-H383

14. Minami N, Head GA (1993) Relationship between cardiovascular hypertrophy and cardiac baroreflex function in spontaneously hypertensive and stroke-prone rats. J Hypertens 11: 523-533

15. Akselrod S, Gordon D, Ubel FA, Shannon DC, Barger AC, Cohen RJ (1981) Power spectrum analysis of the heart rate fluctuation: a quantitative probe of beat-to-beat cardiovascular control. Science 213: 220-222

16. Pomeranz B, Macaulay RJB, Caudill MA et al. (1985) Assessment of autonomic function in humans by heart rate spectral analysis. Am J Physiol 248: H151-H153
17. Pagani M, Lombardi F, Guzzetti S et al. (1986) Power spectral analysis of heart rate and arterial pressure variabilities as a marker of sympathovagal interactions in man and conscious dog. Circ Res 59: 178-193

18. Bernardi L, Ricordi L, Lazzari P et al. (1992) Impaired circadian modulation of sympathovagal activity in diabetes. Circulation 86: 1443-1452

19. Devereux R, Reichek N (1977) Echocardiographic determination of left ventricular mass in man: anatomic validation of the method. Circulation 55: 613-618

20. O'Brien IAD, O'Hare P, Corrall RJM (1986) Heart rate variability in healthy subjects: effects of age and the derivation of normal ranges for tests of autonomic function. $\mathrm{Br}$ Heart J 55: 348-354

21. Maser RE, Pfeifer MA, Dorman JS, Kuller LH, Becker DJ, Orchard TJ (1990) Diabetic autonomic neuropathy and cardiovascular risk. Pittsburgh epidemiology of diabetes complications study III. Arch Intern Med 152: 1218-1222

22. Ziegler D, Spüler M, Dannehl K, Gries FA, Mühlen H (1991) Prevalence of cardiovascular autonomic dysfunction assessed by spectral analysis and standard tests of heartrate variation in newly diagnosed IDDM patients. Diabetes Care 7: 908-911

23. DCCT Research Group (1995) The effect of intensive diabetes therapy on the development and progression of neuropathy. Ann Intern Med 122: 561-568

24. Pickering TG, Gribbin B, Strange-Petersen E, Cunningham DJC, Sleight P (1971) Comparison of the effects of exercise and posture on the baroreflex in man. Circ Res 5: 582-586

25. Parati G, Saul P, Di Rienzo M, Mancia G (1995) Spectral analysis of blood pressure and heart rate variability in evaluating cardiovascular regulation: a critical appraisal. Hypertension 25: 1276-1286

26. Zola B, Khan JK, Juni JE, Vinik AI (1986) Abnormal cardiac function in diabetic patients with autonomic neuropathy in the absence of ischaemic heart disease. J Clin Endocrinol Metab 63: 208-214

27. Maraud L, Gin H, Roudaut R, Aubertin J, Bricaud H (1991) Echocardiographic study of left ventricular function in type 1 diabetes mellitus: hypersensitivity of $\beta$-adrenergic stimulation. Diabetes Res Clin Pract 11: 161-168

28. Koren MJ, Devereux RB, Casale PN, Savage DD, Laragh JH (1991) Relation of left ventricular mass and geometry to morbidity and mortality in uncomplicated essential hypertension. Am Coll Phys 114: 345-352

29. McLenachan JM, Henderson E, Morris KL, Dargie HJ (1987) Ventricular arrhythmias in patients with LVH. N Engl J Med 317: 787-792

30. Tattersall RB, Gill GV (1991) Unexplained sudden death of type 1 diabetic patients. Diabet Med 8: 49-58

31. Sartor G, Dahlquist G (1995) Short term mortality in childhood onset insulin dependent diabetes mellitus: a high frequency of unexpected deaths in bed. Diabet Med 12: 607611

32. Thordarson H, Søvik O (1995) Dead in bed syndrome in young diabetic patients in Norway. Diab Med 12: 782-787

33. Bigger JT, Kleiger RE, Fleiss JL, Rolnitzky LM, Steinman RC, Miller JP (1988) Multicenter Post-Infarction Research Group: components of heart rate variability measured during healing of acute myocardial infarction. Am J Cardiol 61: $205-215$ 